\title{
Wave passage effects on the seismic response of a maglev vehicle moving on multi-span guideway
}

\begin{abstract}
As a seismic wave travels along the separate supports of an extended structure, the structure is subjected to multiple-support excitation due to seismic wave propagation. Considering the seismic wave passage effect, this paper describes seismic analysis of a maglev vehicle moving on a multiply supported gudieway. The guideway system is modeled as a series of simple beams and the vehicle as a four degrees-of-freedom (DOFs) rigid bar equipped with multiple onboard $\mathrm{PI}+\mathrm{LQR}$ hybrid controllers. The controller is used to regulate control voltage for tuning both magnetic forces of uplift levitation and lateral guidance in the maglev system. Numerical studies show that as a maglev vehicle is equipped with more supported magnets then they can provide more control gains for tuning the guidance forces of the moving vehicle, and mitigate seismic-induced lateral vibration of a maglev vehicle running a guideway.
\end{abstract}

\section{Keywords}

maglev transport; multi-support motion; PI + LQR controller; wave passage effect.

\author{
J. D. $\mathrm{Yau}^{*}$ \\ Department of Architecture, Tamkang Univer- \\ sity, New Taipei City 251, Taiwan \\ College of Civil Engineering and Architecture, \\ Zhejiang University, Hangzhou, China \\ Received 14 Jun 2012 \\ In revised form 09 Oct 2012 \\ *Author email: jdyau@mail.tku.edu.tw
}

\section{INTRODUCTION}

With fast progress of train technology and growing demands of ground transportation, high speed rails were constructed for intercity transport $[1,2]$. Unlike conventional wheel/rail transport, maglev (short for "magnetic levitation") transport provides several environmental-friendly advantages, such as low noise, less energy consumption, and low waste gas discharge [3]. For these benefits in energy saving and carbon reduction, maglev transports were deployed in modern cities of Asian countries, for examples, Shanghai Maglev Demonstration Line in China [4,5], Tobukyu Demonstration Line for the "Aichi Expo. 2005" in Japan [6], and the urban maglev transport system (UTM-02) of Daejeon in Korea [7].

From the viewpoint of maglev technology, two kinds of main commercial maglev transport systems have been developed in the world: (1) the electrodynamic suspension (EDS) with repulsive mode [8]; (2) the electromagnetic suspension (EMS) with attractive mode [9]. The EDS system sus- 
pends a train above its guide-rail using magnetic repulsive forces to take the train off the U-shaped guideway. One feature of EDS-type maglev trains is that its magnetic levitation is workable only at high speeds. But the EMS system can lift a train up using attractive forces by the supported magnets between vehicle's levitation frame and guide-rail at any speed, which is the major difference from the EDS system.

Concerning the types of uplift forces to levitate a maglev train running on a guideway, Cai et al. [10] revealed that a concentrated-load vehicle model might gives rise to larger response on both guideway deflections and vehicle accelerations than a distributed-load vehicle model. In addition, Cai and Chen [11] provided a literature review for various aspects of the dynamic characteristics, magnetic suspension systems, vehicle stability, suspension control laws of maglev/guideway coupling systems. Zheng et al. $[12,13]$ developed two kinds of maglev vehicle/guideway coupling models to investigate the dynamic problems of divergence, flutter, and collision on the dynamic stability of a maglev-vehicle traveling on a flexible guideway. Zhao and Zhai [14] modeled the levitation forces as an equivalent spring to investigate vertical random response and ride quality of a maglev vehicle traveling on elevated guideways. Yau [15-19,21] and Yang and Yau [20] carried out a series of dynamic investigations of maglev vehicles traveling over flexible guideways [15], including vibration control of moving vehicle [16], influence of ground settlement [17], horizontal earthquake-induced vibration [18], aerodynamic vibration [19,21], and dynamic interaction of vehicle-guideway system with soil-foundation [20].

Because of the wave passage effect, which considers the time delay of seismic waves arriving at separate supports along a multi-span structure [22], the structure is excited by multiple support movements during earthquakes. Figure 1 shows a maglev vehicle is traveling over a series of guideway girders shaken by lateral ground motion with seismic wave passage effect. To explore the seismic response of dynamic interaction between the maglev-vehicle and the guideway girders, this study adopts an optimal PI $+\mathrm{LQR}$ hybrid controller to regulate the vertical levitation and lateral guidance forces for controlling the vibration of the moving maglev vehicle. By the pseudo-static decomposition method [23], the total response of a seismically-excited structure is separated into the pseudo-static and dynamic components. Then the two sets of differential equations associated with the control equations of electromagnetic forces for the seismically-excited vehicle/guideway system are solved and computed using an iterative approach [20]. Numerical studies demonstrated that the lateral multi-support motion resulted from the seismic wave traveling along the guideway may amplify lateral response of the running vehicle significantly. Even so, a maglev vehicle with more supported magnets can effectively regulate the guidance forces and further mitigate lateral vibration of the vehicle.

\section{GOVERNING EQUATIONS OF MOTION}

For theoretical formulation, the following assumptions are adopted for the present maglev vehicle/guideway model: (1) The guideway system is modeled as a series of simply supported beams with identical properties and the beam is idealized as a linear elastic Bernoulli-Euler beam with uniform section; (2) The maglev vehicle is simulated as a rigid beam supported and guided by multiple magnets; (3) Allowable levitation and guidance gaps at the magnetic wheel should not 
contact with the guide rail; (4) The magnets below the rigid car body (see Fig. 2) are regarded as a series of equal-distant concentrated masses attached to the bottom of rigid bar; (5) The guideway girders are excited by the lateral multi-support motion induced by the seismic wave traveling along the longitudinal direction of the gudieway (see Fig. 2); (6) The time delay between the input voltage and output current on the maglev suspension system is negligible.

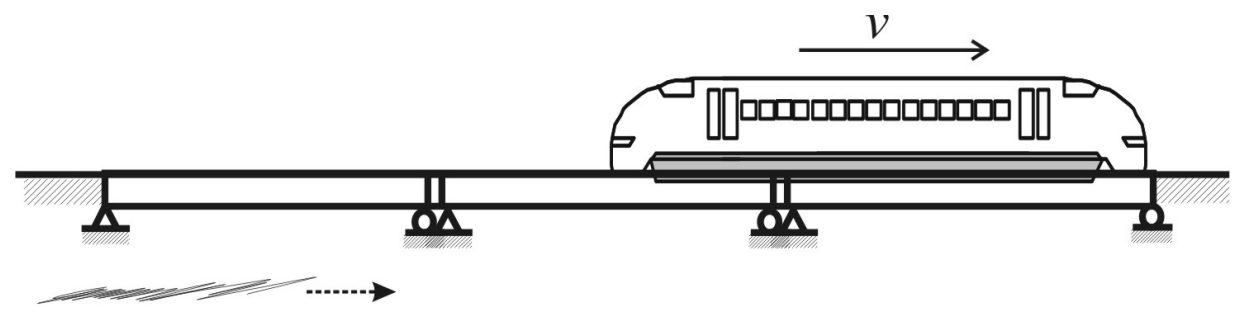

Seismic traveling wave

Figure 1 Schematic diagram of a maglev vehicle moving over multiple guideway girders.

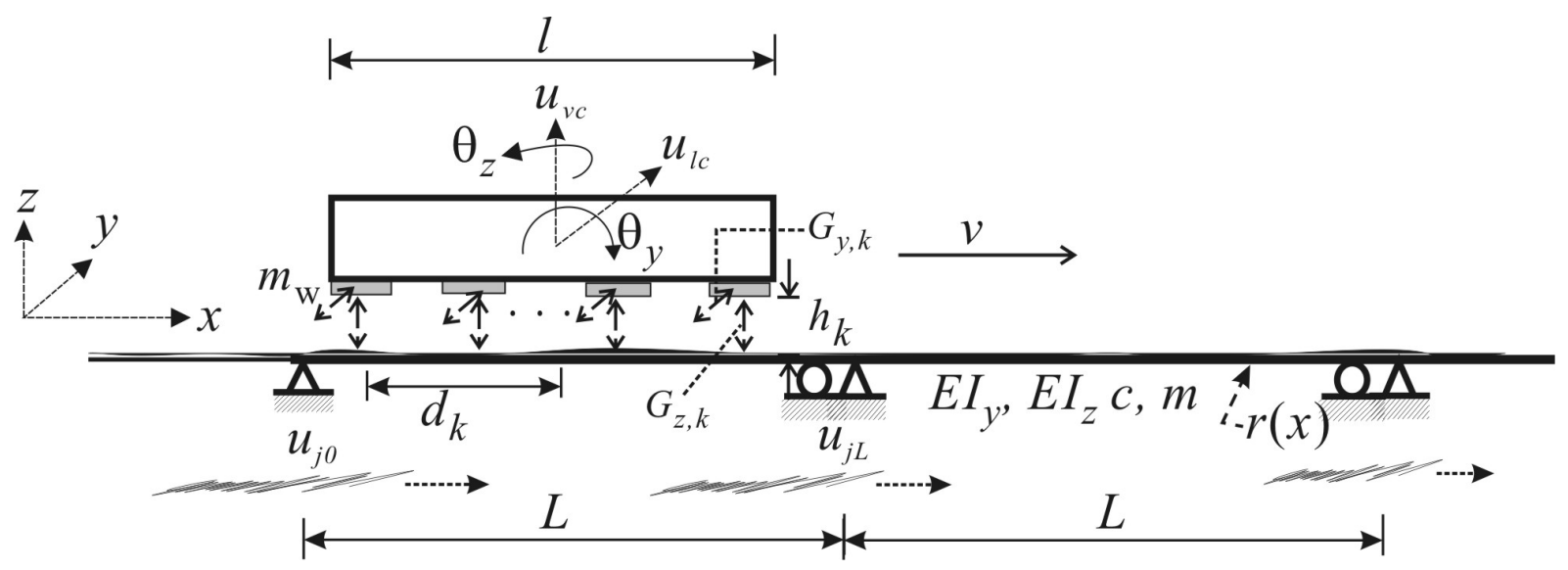

Figure 2 A maglev vehicle/guideway model shaken by seismic traveling wave.

\subsection{Guideway elastic model}

Considering the multi-support motion due to seismic wave passage effect, as shown in Fig. 2, a maglev vehicle supported by multiple magnets with equal-intervals $(d)$ is traveling over a series of simple beams at constant speed $v$. Here, we shall use the following symbols to denote the properties depicted in the schematic diagram of Fig. 2: $m=$ distributed mass of the beam, $c=$ damping coefficient, $E I_{y}=$ flexural rigidity in the $y$ direction, $E I_{z}=$ flexural rigidity in the $z$ direction, $l=$ car length, $m_{\mathrm{w}}=$ lumped mass of magnetic wheel, $m_{v}=$ distributed mass of the rigid car body, and $\left.\theta_{i}\right|_{i=x, y, z}=$ midpoint rotation components of the rigid car body. Then, one can formulate the equations of motion for the $j$ th guideway girder carrying a moving maglev vehicle suspended by multiple magnetic forces as follows:

$$
m \ddot{u}_{y, j}+c_{y} \dot{u}_{y, j}+E I_{y} u_{y, j}^{\prime \prime \prime \prime}=\sum_{k=1}^{K}\left[G_{y, k}\left(i_{k}, h_{y, k}\right) \varphi_{j}\left(x_{k}, t\right)\right],
$$




$$
m \ddot{u}_{z, j}+c_{z} \dot{u}_{z, j}+E I_{z} u_{z, j}^{\prime \prime \prime \prime}=p_{0}-\sum_{k=1}^{K}\left[G_{z, k}\left(i_{k}, h_{z, k}\right) \varphi_{j}\left(x_{k}, t\right)\right]
$$

and

$$
\varphi_{j}\left(x_{k}, t\right)=\delta\left(x-x_{k}\right)\left[H\left(t-t_{k}-\frac{(j-1) L}{v}\right)-H\left(t-t_{k}-\frac{j L}{v}\right)\right]
$$

together with the following boundary conditions with lateral ( $y$-direction) support movements:

$$
\begin{gathered}
u_{y, j}(0, t)=u_{y j 0}(t), u_{y, j}(L, t)=u_{y j L}(t), \\
E I_{z} u_{z, j}^{\prime \prime}(0, t)=E I_{z} u_{z, j}^{\prime \prime}(L, t)=0, \\
u_{z, j}(0, t)=u_{z, j}(L, t)=0, \\
E I_{y} u_{y, j}^{\prime \prime}(0, t)=E I_{y} u_{y, j}^{\prime \prime}(L, t)=0,
\end{gathered}
$$

where $(\bullet)^{\prime}=\partial(\bullet) / \partial x,(\dot{\bullet})=\partial(\bullet) / \partial t, u_{z, j}(x, t)=$ vertical deflection of the $j$ th span, $u_{y, j}(x, t)=$ lateral deflection of the $j$ th span, $L=$ span length, $K=$ number of magnets attached to the rigid levitation frame, $\delta(\bullet)=$ Dirac's delta function, $H(t)=$ unit step function, $k=1,2,3, \ldots, K$ th moving magnetic wheel on the beam, $t_{k}=(k-1) d / v=$ arrival time of the $k$ th magnetic wheel into the beam, $x_{k}=$ position of the $k$-th magnetic wheel on the guide-way, and $\left(G_{y, k}, G_{z, k}\right)=$ lateral guidance and uplift levitation forces of the $k$ th lumped magnet in the vertical and lateral directions.

\subsection{Magnetic forces of uplift levitation and lateral guidance}

As a maglev vehicle moves over guideway shaken by horizontal earthquakes with lateral ground motion, as shown in Fig.2, the lateral support movements to the guideway would affect the riding comfort and maneuverability of the moving vehicle. Thus, guidance forces tuned by the maglev system need to control the lateral motion of the moving maglev vehicle. This study adopts the lateral guidance force $\left(G_{y, k}\right)$ and the uplift levitation force $\left(G_{z, k}\right)$ proposed by Aldo and Alfred [24] to keep and guide the $k$-th magnet of the vehicle. They are expressed as

$$
G_{y, k}=\kappa_{0}\left(\frac{i_{k}(t)}{h_{z, k}(t)}\right)^{2} \kappa_{z, k}
$$




$$
G_{z, k}=\kappa_{0}\left(\frac{i_{k}(t)}{h_{z, k}(t)}\right)^{2}\left(1-\kappa_{y, k}\right)
$$

where $\kappa_{y, k}$ and $\kappa_{z, k}$ represent induced guidance factors and they are given by,

$$
\kappa_{y, k}=\frac{\chi_{k} \times h_{y, k}}{W\left(1+\chi_{k}\right)}, \kappa_{z, k}=\frac{\chi_{k} \times h_{z, k}}{W\left(1+\chi_{k}\right)}
$$

In Eqs. (6)-(7), $\kappa_{0}=\mu_{0} N_{0}^{2} A_{0} / 4=$ coupling factor, $\chi_{k}=\pi h_{y, k} / 4 h_{z, k}, W=$ pole width, $\mu_{0}=$ vacuum permeability, $N_{0}=$ number of turns of the magnet windings, $A_{0}=$ pole face area, $i_{n}(t)=i_{0}+\boldsymbol{l}_{n}(t)=$ electric current, $\boldsymbol{l}_{n}(t)=$ deviation of current, and $\left(i_{0}, h_{\mathrm{y} 0}, h_{\mathrm{z} 0}\right)=$ desired current and air gaps around a specified nominal operating point of the maglev wheels at static equilibrium. And the uplift levitation $\left(h_{y, k}\right)$ and lateral guidance $\left(h_{z, k}\right)$ gaps are respectively given by:

$$
\begin{gathered}
h_{y, k}(t)=h_{y 0}+u_{l, k}(t)-u_{y, j}\left(x_{k}\right), u_{l, k}(t)=u_{l c}(t)+d_{k} \theta_{z} \\
h_{z, k}(t)=h_{z 0}+u_{v, k}(t)-u_{z, j}\left(x_{k}\right)+r\left(x_{k}\right), u_{v, k}(t)=u_{v c}(t)-d_{k} \theta_{y}
\end{gathered}
$$

where $\left(u_{l, k}, u_{v, k}\right)=$ displacements of the $k$ th magnetic wheel in the $y$ and $z$ directions, $\left(u_{l c}, u_{v c}\right)=$ midpoint displacements of the rigid car, $\left(\theta_{y}, \theta_{z}\right)=$ midpoint rotations of the rigid car, $r(x)=$ irregularity of guideway, and $d_{k}=$ location of the $k$ th magnetic wheel to the midpoint of the rigid beam.

As indicated in Eqs. (6)-(8), the motion-dependent nature and guidance factors $\left(\kappa_{y, k}, \kappa_{z, k}\right)$ dominate the control forces of the maglev vehicle-guideway system. Next, the equations of motion of the 4-DOFs tigid maglev vehicle (see Fig. 2) are written as

$$
\begin{gathered}
M_{0} \ddot{u}_{l c}=g(t)+\sum_{k=1}^{K} G_{y, k}, \quad I_{T} \ddot{\theta}_{z}=g(t) \times l+\sum_{k=1}^{K}\left[G_{y, k} d_{k}\right] \\
M_{0} \ddot{u}_{v c}=-p_{0}+\sum_{k=1}^{K} G_{z, k}, \quad I_{T} \ddot{\theta}_{y}=-\sum_{k=1}^{K}\left[G_{z, k} d_{k}\right]
\end{gathered}
$$

in which $M_{0}=m_{v} l+K m_{w}=$ lumped mass of the vehicle, $g(t)=$ control force to tune the lateral response of the maglev vehicle, $I_{T}=$ total mass moment of inertia of the rigid car, and $p_{0}=M_{0} g=$ lumped weight of the maglev vehicle.

\section{LATERAL VIBRATION CONTROL BASED ON LQR ALGORITHM}

LQR (Linear Quadratic Regulation) algorithm has been widely used in optimal control because of simplicity, reliability, robustness, and stability in a closed-loop system [25].Thus, the equations of 
lateral motion for the maglev vehicle in Eqs. (11) and (12) are rewritten as

$$
\begin{gathered}
M_{0} \ddot{u}_{l c}=g(t)+f(t), f(t)=\sum_{k=1}^{K}\left[G_{y, k}\right] \\
I_{T} \ddot{\theta}_{z}=g(t) l+\mathfrak{M}(t), \mathfrak{M}(t)=\sum_{k=1}^{K}\left[G_{y, k} d_{k}\right]
\end{gathered}
$$

It is noted that this study regards the control moment $g(t) l$ exerting at the maglev vehicle in zdirection of Eqs. (14) is proportional to the control force $g(t)$.

\subsection{Determination of tuning parameters}

Since Eqs. (13) and (14) are un-coupled each other, introducing the state space of $\langle y\rangle=\left\langle\begin{array}{ll}u_{l c} & \dot{u}_{l c}\end{array}\right\rangle$ into Eq. (13) yields the following matrix equation

$$
\begin{aligned}
& \{\dot{y}\}=[A]\{y\}+\{B\} g(t)+\{C\} f(t) \\
& {[A]=\left[\begin{array}{cc}
0 & 1 \\
0 & 0
\end{array}\right],\{B\}=\left\{\begin{array}{c}
0 \\
1 / M_{0}
\end{array}\right\},} \\
& \{C\}=\left\{\begin{array}{c}
0 \\
1 / M_{0}
\end{array}\right\}, g(t)=[G]\{y\}
\end{aligned}
$$

where $\{y\}=\langle y\rangle^{\mathrm{T}}$ and $[G]$ represents the control gain matrix. In this control algorithm, the control force $g(t)$ is determined by minimizing the following quadratic cost index [25]

$$
J=\int_{0}^{t_{f}}\left[\{y\}^{T}[Q]\{y\}+R^{2}\right] d t
$$

Here, $[Q]$ is a symmetric positive semi-definite weighting matrix for the performance of a structural system and $R$ the weighting parameter for the input control force. To minimize the performance index $J$ in Eq. (16), the Riccati equation [25] is usually used to obtain the following Riccati matrix $[P]$ and the control gain matrix $[G]$, i.e.,

$$
\begin{gathered}
{[P][A]-\frac{1}{2}[P]\{B\} R^{-1}\{B\}^{T}[P]+[A]^{T}[P]+2[Q]=[0]} \\
{[G]=\frac{-1}{2} R^{-1}[B]^{T}[P]}
\end{gathered}
$$

In this study, the weighting matrix $[Q]$ is represented by 


$$
[Q]=\left[\begin{array}{cc}
k_{w} & 0 \\
0 & 0
\end{array}\right]
$$

where $k_{w}$ represents the stiffness weighting parameter. The solution of the Riccati matrix $[P]$ in Eq. (17)and the corresponding control gain $g(t)$ in Eqs. (15) are respectively given as follows [31]:

$$
\begin{gathered}
{[P]=2 M_{0}\left[\begin{array}{cc}
\sqrt{\sqrt{k_{w} / R} \times k_{w} / M_{0}} & \sqrt{k_{w} R} \\
\sqrt{k_{w} R} & \sqrt{2 M_{0} R \sqrt{k_{w} R}}
\end{array}\right]} \\
g(t)=[G]\{y\}=-\left(\sqrt{2 M_{0} \sqrt{k_{w} / R}} \times \dot{u}_{l c}+\sqrt{k_{w} / R} \times u_{l c}\right)
\end{gathered}
$$

Let $R=k_{w} / \Psi^{2}$, the coefficient $\Psi$ represents the relative importance of control performance in response suppression [25]. Introducing the derived control force $g(t)$ shown in Eq. (21) into Eqs. (13) and (14) yields the following equations for a controlled maglev-vehicle in lateral direction:

$$
\begin{gathered}
M_{0} \ddot{u}_{l c}+\sqrt{2 M_{0} \Psi} \times \dot{u}_{l c}+\Psi u_{l c}=\sum_{k=1}^{K}\left[G_{y, k}\right] \\
I_{T} \ddot{\theta}_{z}+\sqrt{2 M_{0} \Psi} \times l \dot{\theta}_{z}+\Psi l \theta_{z}=\sum_{k=1}^{K}\left[G_{y, k} d_{k}\right]
\end{gathered}
$$

\subsection{Determination of coupling factor}

From the condition of static equilibrium for the suspended maglev vehicle with initial gaps of $\left(\mathrm{h}_{\mathrm{y} 0}, \mathrm{~h}_{\mathrm{z} 0}\right)$ in both lateral and vertical directions, respectively, one can obtain the following static electromagnetic force at the $k$-th magnetic wheel from Eqs. (6) and (7)

$$
\begin{gathered}
G_{y 0}=\kappa_{0} \gamma_{z 0}^{2}\left[\frac{\chi_{0} \times h_{z 0} / W}{1+\chi_{0}}\right], \\
G_{z 0}=\kappa_{0} \gamma_{z 0}^{2}\left[1-\frac{\chi_{0} \times h_{y 0} / W}{1+\chi_{0}}\right]=\frac{p_{0}}{K}
\end{gathered}
$$

Here, $\gamma_{z 0}=i_{0} / h_{z 0}$ and $\chi_{0}=\pi h_{y 0} / 4 h_{z 0}$. To keep the maglev vehicle in static equilibrium at 
initial lateral air gap of $h_{y 0}$, the control force required from the LQR-controlled magnetic actuator can be represented by:

$$
\Psi_{0} h_{y 0}=\sum_{k=1}^{K}\left[G_{y 0}\right]
$$

where $\Psi_{0}$ means the initial stiffness parameter tuned by the LQR-controlled magnetic actuator. Solving the simultaneous equations of Eqs. (24)-(26) yields the following initial parameters

$$
\kappa_{0}=\frac{p_{0} \gamma_{z 0}^{-2}}{K}\left[1-\frac{\chi_{0} \times h_{y 0} / W}{1+\chi_{0}}\right]^{-1}
$$

with $\Psi_{0}=\frac{\pi p_{0} / 4 W}{1+\left(1-h_{y 0} / W\right) \chi_{0}}$. For the special case of $h_{y 0}=0$, the coupling factor becomes $\kappa_{0}=p_{0} / K \gamma_{z 0}^{2}$, which is reduced to the case of a maglev vehicle at vertical static equilibrium without initial lateral movement [16].

\subsection{Nonlinear actuator dynamics}

As a maglev vehicle moves over guideway, the control actuator needs to provide additional gains for tuning the controller, let $\Psi=\Psi_{0}+\psi$ and consider the initial lateral air gap of $h_{y 0}$, thus, the equation of lateral motion for the moving maglev vehicle becomes

$$
\begin{gathered}
M_{0} \ddot{u}_{l c}+\sqrt{2 M_{0}\left(\Psi_{0}+\psi\right)} \times \dot{u}_{l c}+\left(\Psi_{0}+\psi\right) u_{l c}=-\Psi_{0} h_{y 0}+\sum_{k=1}^{K}\left[G_{y, k}\right] \\
I_{T} \ddot{\theta}_{z}+\sqrt{2 M_{0} \Psi} \times l \dot{\theta}_{z}+\Psi l \theta_{z}=\sum_{k=1}^{K}\left[G_{y, k} d_{k}\right]
\end{gathered}
$$

Here, $\psi$ represents additional tuning stiffness gain as the maglev vehicle runs on the guideway subjected to lateral ground motion with traveling wave effect and $\psi$ is set $\Psi_{0} / 4$.

\section{CONTROL EQUATION OF THE MAGLEV SUSPENSION SYSTEM}

By the theory of electromagnetic circuits, the electromagnetic equation of magnet current and control voltage for the $n$th electric magnets in the maglev suspension system is given by

$$
\Gamma_{0} \frac{d\left(i_{n} / h_{z, n}\right)}{d t}+R_{0} i_{n}=V_{n}
$$


where $\Gamma_{0}=$ initial inductance of the coil winding the suspension magnet, $R_{0}=$ coil resistance of electronic circuit, and $V_{n}=$ control voltage. To control the levitation forces between the mgalev vehicle and guideway, an onboard PI control algorithm [26,27] is employed to regulate control voltage of the maglev system. Let us adopt the variable transformation as $\gamma_{z n}=i_{n} / h_{z, n}$, the control voltage $V_{n}$ can be expressed in terms of current error of $e_{n}\left(=i_{0} / h_{z 0}-i_{n} / h_{z, n}=\gamma_{z 0}-\gamma_{z n}\right)$ in the control process by using PI (Proportional-Integral) tuning algorithm as [27]

$$
V_{n}=K_{p} e_{n}+K_{i} \int_{0}^{t} e_{n} d t
$$

where $K_{p}=$ proportional gain and $K_{i}=$ integral gain. In this study, the constant tuning gains $\left(K_{p}, K_{i}\right)$ are used and determined by the Z-N tuning rule [26]. Then substituting Eq. (30) into Eq. (31) and differentiating this equation with respect to time, one can achieve the following differential equation for control current error

$$
\Gamma_{0} \ddot{e}_{n}+\left(K_{p}+R_{0} h_{z, n}\right) \dot{e}_{n}+\left(K_{i}+R_{0} \dot{h}_{z, n}\right) e_{n}-R_{0} \gamma_{z 0}\left(\dot{u}_{v c}-d_{k} \dot{\theta}_{y}\right)=R_{0} \gamma_{z 0}\left(\dot{r}\left(x_{k}\right)-\dot{u}_{z j}\right)
$$

With the aid of the control error function $e_{n}$ and the parameter $\gamma_{z 0}=i_{0} / h_{z 0}$ at static equilibrium, the equations of motion in Eqs. (11) and (12) for the controlled maglev vehicle become

$$
\begin{gathered}
M_{0} \ddot{u}_{l c}+\sqrt{2 M_{0}\left(\Psi_{0}+\psi\right)} \times \dot{u}_{l c}+\left(\Psi_{0}+\psi\right) u_{l c}=-\Psi_{0} h_{y 0}+\Upsilon_{0} \sum_{k=1}^{K}\left[\left(\frac{e_{k}}{\gamma_{z 0}}-1\right)^{2}\left[\frac{h_{z, k} \chi_{k}}{W\left(1+\chi_{k}\right)}\right]\right] \\
I_{y} \ddot{\theta}_{z}+\sqrt{2 M_{0}\left(\Psi_{0}+\psi\right)} \times \dot{\theta}_{z}+\left(\Psi_{0}+\psi\right) l \theta_{z}=\Upsilon_{0} \sum_{k=1}^{K}\left[\left(\frac{e_{k}}{\gamma_{z 0}}-1\right)^{2}\left[\frac{h_{z, k} \chi_{k}}{W\left(1+\chi_{k}\right)}\right] d_{k}\right] \\
M_{0} \ddot{u}_{v c}=-p_{0}+\Upsilon_{0} \sum_{k=1}^{K}\left(\frac{e_{k}}{\gamma_{z 0}}-1\right)^{2}\left[1-\frac{\chi_{k} \times h_{y, k}}{W\left(1+\chi_{k}\right)}\right] \\
I_{T} \ddot{\theta}_{y}=\Upsilon_{0} \sum_{k=1}^{K}\left[\left(\frac{e_{k}}{\gamma_{z 0}}-1\right)^{2}\left(1-\frac{\chi_{k} \times h_{y, k}}{W\left(1+\chi_{k}\right)}\right) d_{k}\right]
\end{gathered}
$$

Where

$$
\Upsilon_{0}=\frac{\left(1+\chi_{0}\right) p_{0} / K}{1+\chi_{0}\left(1-h_{y 0} / W\right)}
$$


Then combinating Eqs. (32)-(34) yields the following matrix equation of motion for the maglev vehicle equipped with onboard controllers

$$
\left[m_{v}\right]\left\{\ddot{u}_{v}\right\}+\left[c_{v, k}\right]\left\{\dot{u}_{v}\right\}+\left[k_{v}\right]\left\{u_{v}\right\}=\left\{f_{v}\right\},
$$

in which $\left\{u_{v}\right\}=$ displacement vector, $\left\{f_{v}\right\}=$ force vector, and $\left(\left[k_{v}\right],\left[c_{v}\right],\left[m_{v}\right]\right)$ means structural matrices of the maglev vehicle.

\section{METHOD OF SOLUTION FOR FLEXIBLE GUIDEWAY GIRDERS}

As shown in Eqs. (1) and (4), it is a differential equation associated with time-dependent boundary conditions. The beam response to lateral multiple support excitations is divided into two parts [28]: (1) the pseudo-static displacement $\left(U_{y, j}\right)$ due to the relative support motions of the beam, and $(2)$ the dynamic component $\left(u_{d j}\right)$ caused by the moving vehicle and seismic excitations. This approach is called pseudo-static decomposition method. Thus the total lateral displacement of the seismically-excited beam is represented by [16]

$$
\begin{aligned}
& u_{y, j}(x, t)=U_{y, j}(x, t)+u_{d j}(x, t) \\
& U_{y, j}(x, t)=u_{y j 0}(t)+\left(u_{y j L}(t)-u_{y j 0}(t)\right) \frac{x}{L} \\
& u_{d j}(x, t)=\sum_{n=1} q_{y, j n}(t) \sin \frac{n \pi x}{L},
\end{aligned}
$$

where the pseudo-static displacement of $U_{y, j}(x, t)$ represents rigid body motion due to relative support motions of $\left(u_{y j, 0}, u_{y j, L}\right)$, and the dynamic deflection of $u_{d j}(x, t)$ is induced by inertial effect of beam vibration. As shown in Eqs. (2) and (5), the vertical deflection $u_{z, j}(x, t)$ of the beam with homogeneous boundary conditions can be approximated by [29]

$$
u_{z, j}(x, t)=\sum_{n=1} q_{z, j n}(t) \sin \frac{n \pi x}{L}
$$

Here, $\left(q_{y, j n}, q_{z, j n}\right)$ are the generalized coordinates associated with the $n$th vibration mode in the $y$ and $z$ directions of the $j$ th span.

By Galerkin's method, the generalized equations of motion for the $n$th modal system of the $j$ th beam in the $y$ (lateral) and $z$ (vertical) directions are respectively given by:

$$
\begin{gathered}
m \ddot{q}_{y, j n}+c_{y, n} \dot{q}_{y, n}+m \omega_{y n}^{2} q_{y, j n}=p_{y, j n}-\frac{2}{n \pi}\left[m \ddot{\Pi}_{y, j n}+c_{y, n} \dot{\Pi}_{y, j n}\right] \\
m \ddot{q}_{z, j n}+c_{z, n} \dot{q}_{y, n}+m \omega_{z n}^{2} q_{z, j n}=p_{z, j n}
\end{gathered}
$$


where $\left(c_{y, n}, c_{z, n}\right)=$ the $n$th modal damping coefficient, $\left(\omega_{y, n}, \omega_{z, n}\right)=$ the $n$th natural frequency, and

$$
\begin{aligned}
& \omega_{y, n}=\left(\frac{n \pi}{l}\right)^{2} \sqrt{\frac{E I_{z}}{m}}, \omega_{z, n}=\left(\frac{n \pi}{l}\right)^{2} \sqrt{\frac{E I_{y}}{m}} \\
& \Pi_{y, j n}=\left(u_{y j 0}(t)-u_{y j L}(t) \times \cos n \pi\right),
\end{aligned}
$$

The generalized magnetic forces of $\left(p_{y, j n}, p_{z, j n}\right)$ are given by

$$
\begin{gathered}
p_{y, j n}=\frac{2}{L} \sum_{k=1}^{K}\left[G_{y, k} \Phi_{j n}(t)\right], \\
p_{z, j n}=\frac{2}{L} \sum_{k=1}^{K}\left[\left(-\frac{p_{0}}{K}+G_{z, k}\right) \Phi_{j n}(t)\right]
\end{gathered}
$$

and

$$
\Phi_{j n}(t)=\sin \frac{n \pi v}{L}\left(t-t_{k}\right) \times\left[H\left(t-t_{k}-\frac{(j-1) L}{v}\right)-H\left(t-t_{k}-\frac{j L}{v}\right)\right]
$$

\section{APPLICATIONS OF THE INCREMENTAL-ITERATIVE APPROACH}

Because of motion-dependent and non-contact nature of electromagnetic forces, the nonlinear dynamic analysis of the maglev vehicle/guideway system needs to be solved by iterative method. The numerical procedure of incremental-iterative dynamic analysis conventionally involves three phases: predictor, corrector, and equilibrium checking. Detailed information about the incremental-iterative procedure for nonlinear dynamic analysis of maglev vehicle/guieway interaction is available in references [15-21]. Figure 3 shows the analysis flow chart to carry out the nonlinear dynamic analysis for the vibration control and interaction responses of maglev vehicle/guideway system shaken by seismic loads. It is noted that (1) the structure matrices in Eqs. (36), (39), and (40) for the dynamic interactions of maglev vehicle/guideway system should be updated at each iteration; (2) the root mean square $\beta_{\text {tol }}$ of the sum of unbalanced forces for the maglev vehicle/guideway interaction system, that is,

$$
\beta_{t o l}=\left[\sum_{k=1 \ldots}\left(\Delta f_{v k, t+\Delta t}^{i-1}\right)^{2}+\sum_{n=1 \ldots}\left(\Delta p_{n, t+\Delta t}^{i-1}\right)^{2}\right]^{1 / 2}
$$

is larger than a preset tolerance, say $10^{-3}$, iteration for removing the unbalanced forces involving 
the two phases of predictor and corrector should be repeated. Here, $\Delta p_{n, t+\Delta t}^{i-1}=$ the unbalanced force between the external force $p_{n, t+\Delta t}^{i-1}$ and the effective internal forces $f_{n, t+\Delta t}^{i-1}$ for the $n$-th generalized system at the $i$-th iteration of time $t+\Delta t$, and $\Delta f_{v k, t+\Delta t}^{i-1}=$ the unbalanced force for the $k$ th maglev wheels to lift up the maglev vehicle.

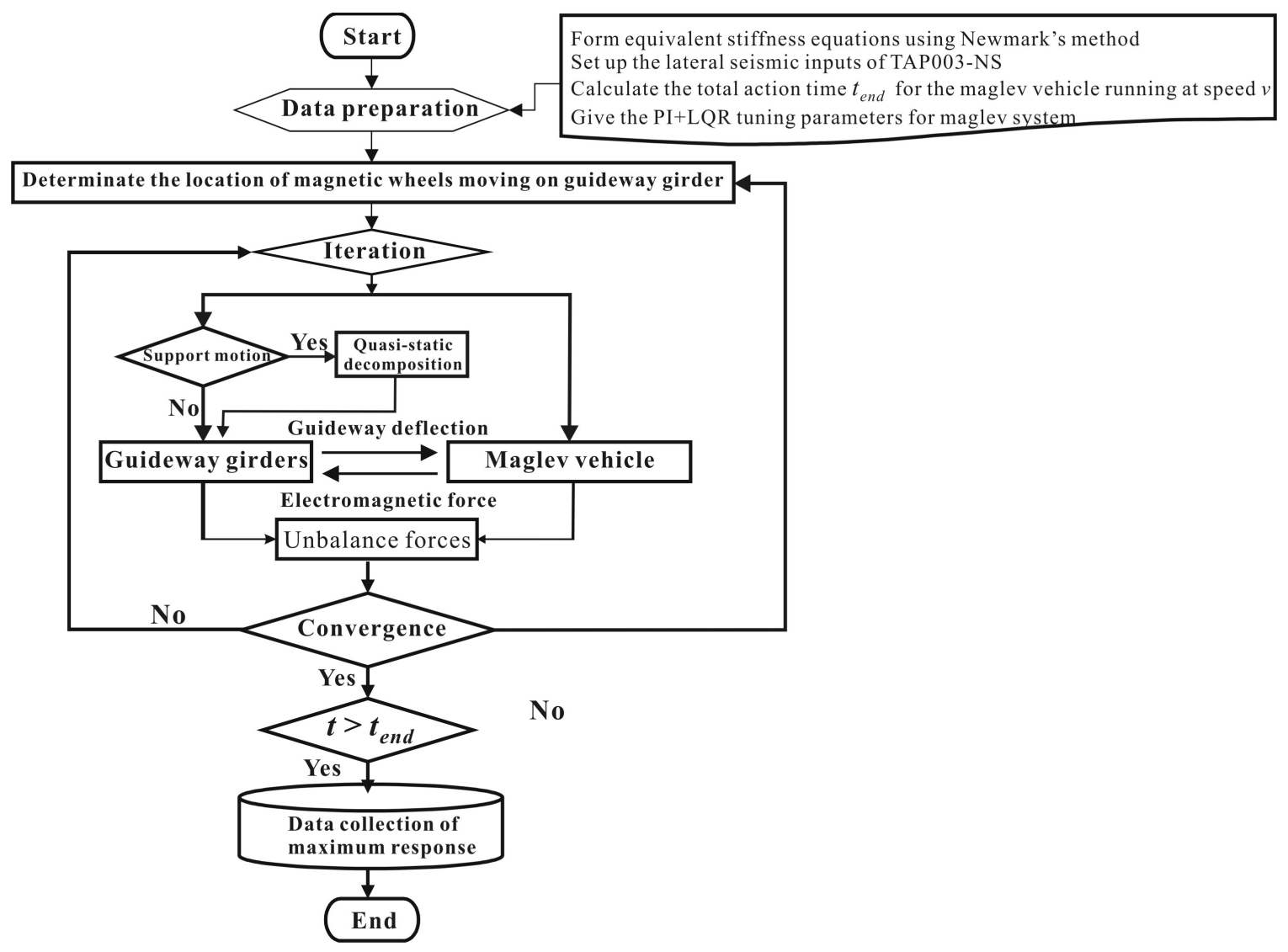

Figure 3 Flow chart of incremental-iterative procedure

\section{NUMERICAL INVESTIGATIONS}

Figure 2 shows a maglev vehicle suspended by multiple magnets is traveling over a series of identical guideway girders with constant speed $v$. The properties of the guideway girder and the maglev vehicle are listed in Tables 1 and 2, respectively. For comparison, let us consider two maglev vehicle models levitated by multiple magnetic wheels (see Table 2). They are named MG-1 and MG-2, respectively. Here, MG-1 represents the maglev vehicle levitated by 6 magnets and MG-2 by 16 magnets. To account for the random nature and characteristics of guide-rail irregularity in practice [4], the following power spectrum density (PSD) function used by the Federal Railroad Administration (FRA) [1] is given to simulate the vertical profile of track geometry variations 


$$
S(\Omega)=\frac{A_{v} \Omega_{c}^{2}}{\left(\Omega^{2}+\Omega_{r}^{2}\right)\left(\Omega^{2}+\Omega_{c}^{2}\right)},
$$

where $\Omega=$ spatial frequency, and $A_{v},\left(=1.5 \times 10^{-7} \mathrm{~m}\right), \Omega_{r}\left(=2.06 \times 10^{-6} \mathrm{rad} / \mathrm{m}\right)$, and $\Omega_{c}(=0.825$ $\mathrm{rad} / \mathrm{m})$ are relevant parameters. Figure 4 shows the vertical profile of track irregularity for simulating rail geometry variations in this study.

Table 1 Properties and natural frequencies of the guideway.

\begin{tabular}{llllllll}
\hline $\begin{array}{l}\mathrm{L} \\
(\mathrm{m})\end{array}$ & $\mathrm{N}$ & $\begin{array}{c}\mathrm{EI}_{\mathrm{y}} \\
\left(\mathrm{kN} \mathrm{m}^{2}\right)\end{array}$ & $\begin{array}{c}\mathrm{EI}_{\mathrm{z}} \\
\left(\mathrm{kN} \mathrm{m}^{2}\right)\end{array}$ & $\begin{array}{l}\mathrm{m} \\
(\mathrm{t} / \mathrm{m})\end{array}$ & $\begin{array}{l}\mathrm{c} \\
(\mathrm{kN}-\mathrm{s} / \mathrm{m} / \mathrm{m})\end{array}$ & $\begin{array}{l}\mathrm{f}_{\mathrm{v} 1} \\
(\mathrm{~Hz})\end{array}$ & $\begin{array}{l}\mathrm{f}_{\mathrm{L} 1} \\
(\mathrm{~Hz})\end{array}$ \\
\hline 20 & 80 & $2.43 \times 10^{6}$ & $2.40 \times 10^{8}$ & 1.5 & 0.94 & 5.0 & 50.0 \\
\hline
\end{tabular}

$f_{v 1}=$ the first natural frequency in vertical direction, $f_{L 1}=$ the first natural frequency in lateral direction

Table 2 Properties of the maglev vehicle

\begin{tabular}{lllllllllllll}
\hline Type & $\begin{array}{l}p_{0} \\
(\mathrm{kN})\end{array}$ & $\begin{array}{l}\mathrm{h}_{\mathrm{z} 0} \\
(\mathrm{~m})\end{array}$ & $\begin{array}{l}\mathrm{h}_{\mathrm{y} 0} \\
(\mathrm{~m})\end{array}$ & $\mathrm{K}$ & $\begin{array}{l}\mathrm{m}_{\mathrm{v}} \\
(\mathrm{kg} / \mathrm{m})\end{array}$ & $\begin{array}{l}\mathrm{I}_{\mathrm{T}} \\
\left(\mathrm{kg}-\mathrm{m}^{2}\right)\end{array}$ & $\begin{array}{l}\mathrm{m}_{\mathrm{w}} \\
(\mathrm{kg})\end{array}$ & $\begin{array}{l}\mathrm{i}_{0} \\
(\boldsymbol{\Omega})\end{array}$ & $\begin{array}{l}\mathrm{R}_{0} \\
(\mathrm{~A})\end{array}$ & $\begin{array}{l}\mathrm{W} \\
(\mathrm{m})\end{array}$ & $\begin{array}{l}\Psi_{0} \\
(\mathrm{kN} / \mathrm{m})\end{array}$ \\
\hline MG-1 & 205.815 & 0.02 & 0.002 & 6 & 1200 & $5.06 \times 10^{4}$ & 500 & 25 & 1.0 & 0.1 & 1500 \\
\hline MG-2 & 205.8 & 15 & 0.02 & 0.002 & 16 & 1200 & $3.30 \times 10^{4}$ & 187.5 & 25 & 1.0 & 0.1 & 1500 \\
\hline
\end{tabular}

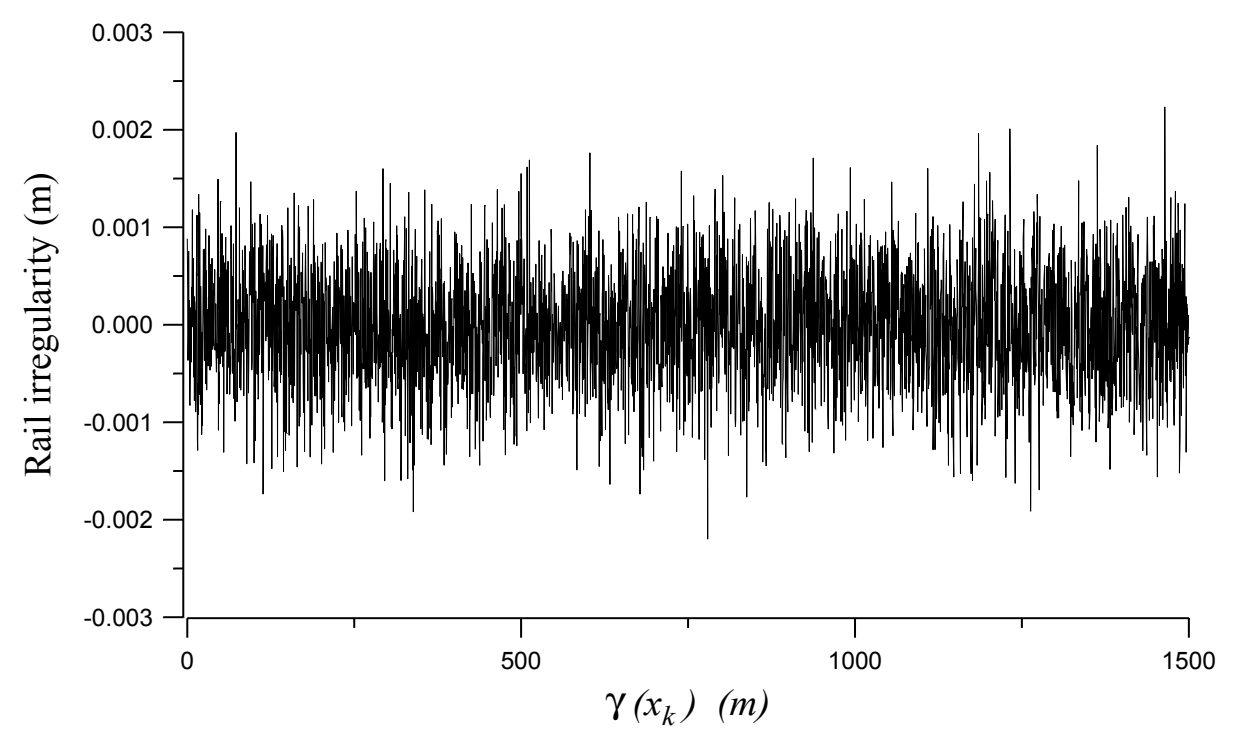

Figure 4 Rail irregularity (vertical profile). 
For a ground transportation system, the acceleration response of running vehicles is usually used to evaluate the ride comfort of passenger cabins and running safety of the maglev system. It was well known that if the acceleration response, rather than the displacement response, of a structure is of concern, the contribution of higher modes has to be included in computation [28]. From the convergent verification of computed results of a beam structure under moving train loads in references [29,30], the first 20 modes of shape functions in Eqs. (26) are sufficient to compute the acceleration response of a simple beam. In addition, the maximum accelerations in vertical $\left(a_{v, \max }\right)$ and lateral $\left(a_{l, \max }\right)$ directions of the maglev vehicle are respectively defined as:

$$
a_{v, \max }=\max \left(\left|\ddot{u}_{v c}+d_{k} \ddot{\theta}_{y}\right|_{k=1,2, \ldots, K}\right), \quad a_{l, \max }=\max \left(\left|\ddot{u}_{l c}+d_{k} \ddot{\theta}_{z}\right|_{k=1,2, \ldots, K}\right)
$$

In the following examples, the time step of $0.005 \mathrm{~s}$ and the ending time of $t_{\text {end }}=(N L+l) / v$ are employed to compute the dynamic response of the traveling maglev vehicle. Here, $N$ is the span number of the guideway girders considered.

\subsection{Application of the $\mathrm{Z}-\mathrm{N}$ tuning rule}

As a mathematical model for a control process is not available, the Ziegler-Nicholas (Z-N) tuning rule offers a useful approach to determine the optimal parameters of a PI controller, by which the PI parameters are given: $K_{p}=0.45 K_{c r}$ and $K_{i}=0.54 K_{c r} / T_{c r}$ [27]. Here, $K_{c r}$ means the critical proportional gain by increasing only the proportional parameter (i.e., $\left.K_{i}=0\right) K_{p}$ from 0 to a critical value $K_{c r}$ so that the output first exhibits an oscillation with a critical period $T_{c r}[27,31]$.

Let the maglev vehicle cross the multi-span guideway with constant speed of $100 \mathrm{~km} / \mathrm{h}$. By trials for different values of the proportional gain $K_{p}$ subject to $h_{z k}>0$, the time history response of the average control error $\sum_{k=1}^{K} e_{k} /\left(K \gamma_{z 0}\right)$ to oscillate has been plotted in Fig. 5. Table 3 has listed the corresponding optimal PI parameters for the maglev vehicles of MG-1 and MG-2. Figures 6 and 7 draw the time history responses of midpoint acceleration of the maglev vehicle and the first guideway girder, respectively. Since the MG-1 has larger mass moment of inertia $\left(I_{T}\right)$ against pitching rotation than the MG-2, the dynamic response of the MG-2 is smaller than that of the MG-1. In the following examples, the proposed PI+LQR hybrid controller with the optimal PI and LQR parameters are employed to regular the control force of the running maglev vehicles.

Table 3 Optimal PI parameters based on the Z-N tuning rule

\begin{tabular}{lllll}
\hline Type & $\mathrm{K}_{\mathrm{cr}}$ & $\mathrm{T}_{\mathrm{cr}}(\mathrm{s})$ & $\mathrm{K}_{\mathrm{p}}\left(=0.45 \mathrm{~K}_{\mathrm{cr}}\right)$ & $\mathrm{K}_{\mathrm{i}}\left(=0.54 \mathrm{~K}_{\mathrm{cr}} / \mathrm{T}_{\mathrm{cr}}\right)$ \\
\hline MG-1 & 0.2 & 0.65 & 0.130 & 0.166 \\
\hline MG-2 & 0.2 & 0.67 & 0.134 & 0.161 \\
\hline
\end{tabular}

Latin American Journal of Solids and Structures 10(2013) $981-1000$ 


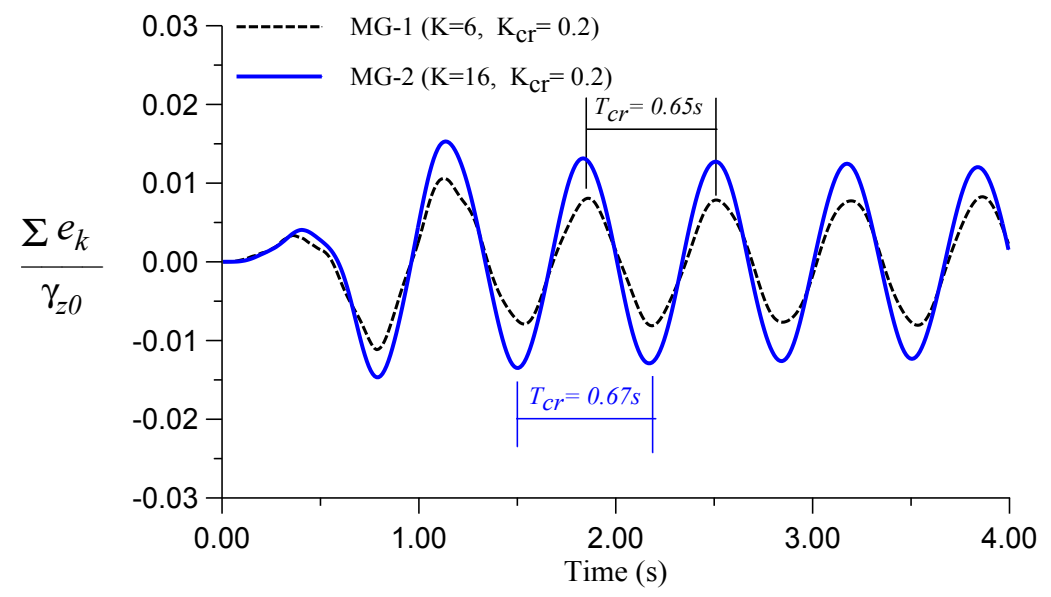

Figure 5 Transient oscillation with critical period $T_{c r}$
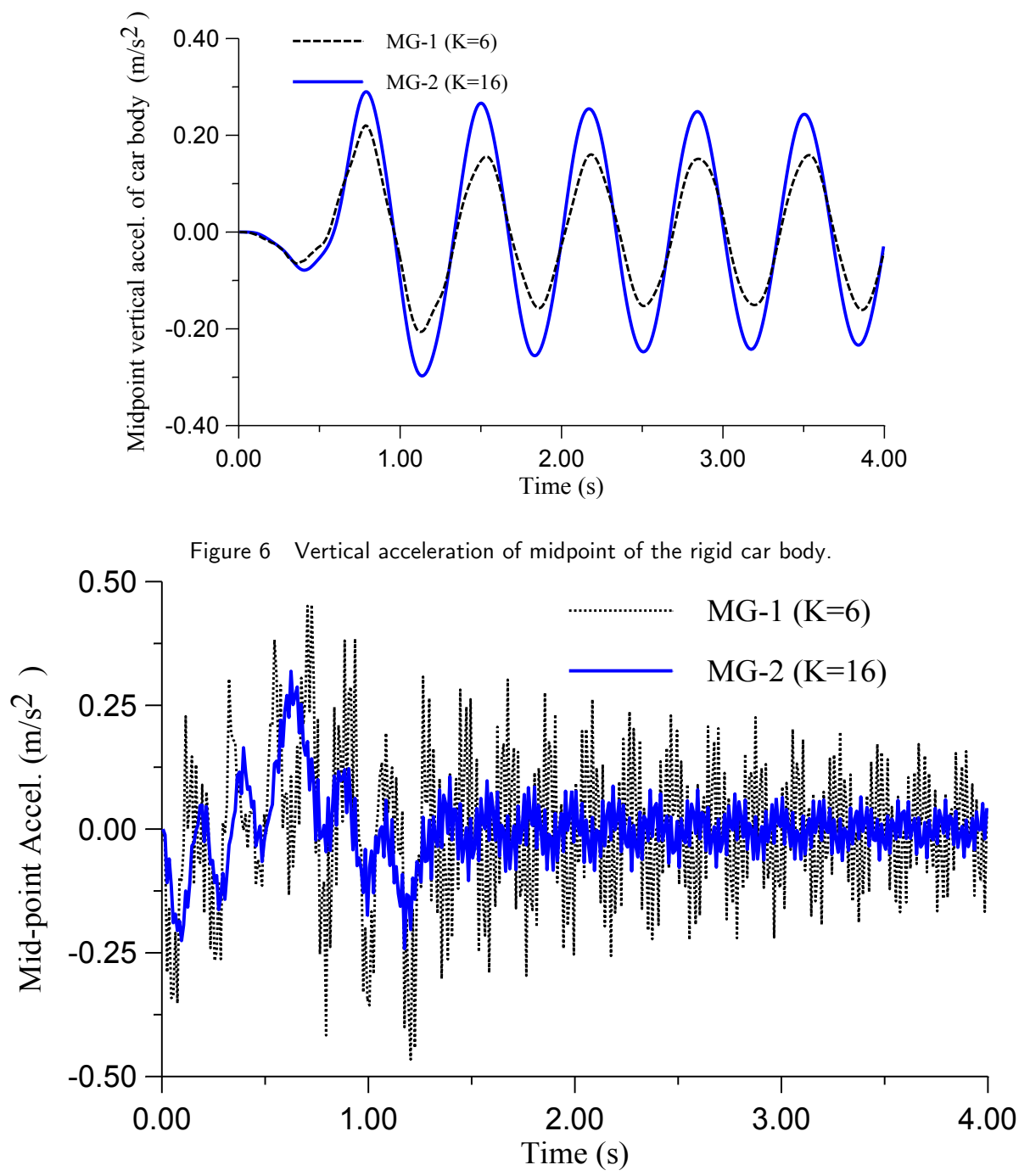

Figure 7 Response of mid-span acceleration of the first guide-way girder. 


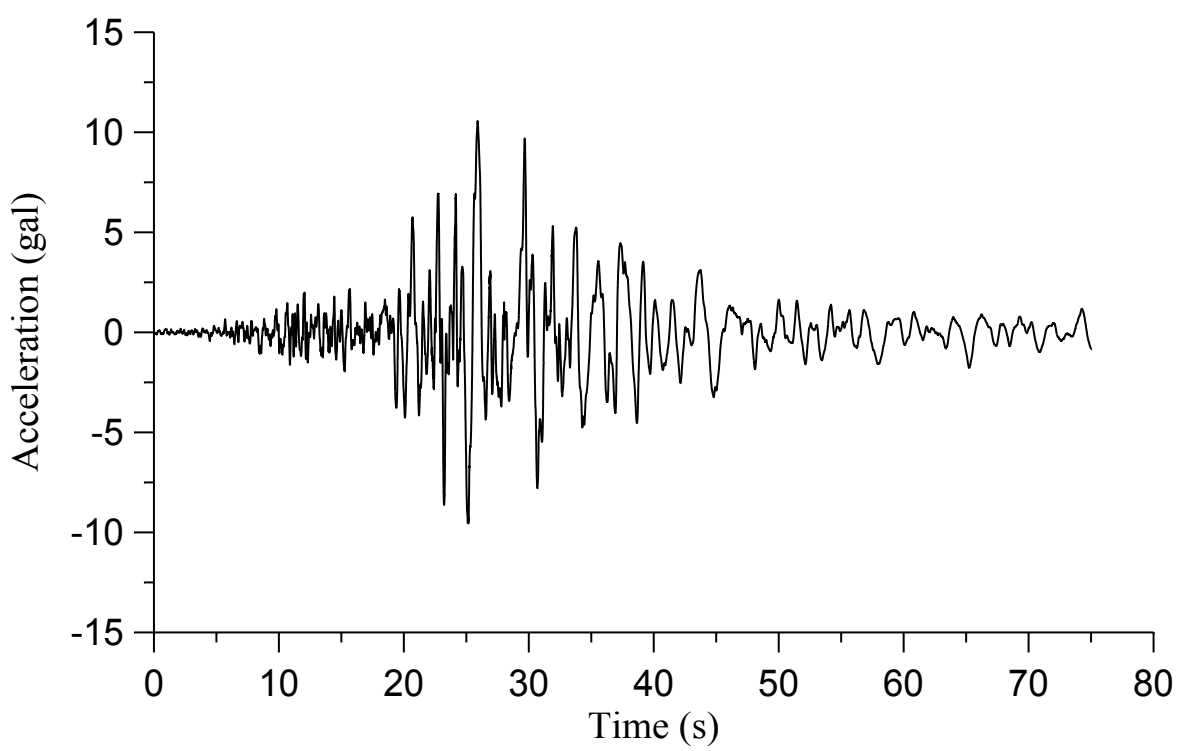

Figure 8 Scaled acceleration histogram recorded at Taipei during the 1999 Chi-Chi Earthquake in Taiwan, NS-component.

\subsection{Effect of uniform support motion}

To investigate the influence of lateral seismic ground motion on the moving maglev vehicles, the far-field ground motion of TAP003 station recorded at Taipei during the 1999 Chi-Chi Earthquake in Taiwan [1] is used to simulate the lateral seismic support inputs with traveling wave effect. Hence, the seismic effect of vertical ground motion on structures is assumed to be negligible in this study. Figure 8 plots the histogram of horizontal ground acceleration in the NS direction, in which the PGA (peak ground acceleration) has been scaled down to 11 gal $\left(=10.8 \mathrm{~cm} / \mathrm{s}^{2}\right)$. First, let us consider the special case all the guideway girders are subjected to uniformly lateral support motion. Figures 9 and 10 depict the maximum lateral $\left(a_{l, m a x}\right)$ and vertical $\left(a_{v, \max }\right)$ accelerations of the maglev vehicles against moving speed $(v)$ ranged from $40 \mathrm{~km} / \mathrm{h}$ to $100 \mathrm{~km} / \mathrm{h}$., respectively. They are respectively denoted as $a_{l, \max }-v$ plot and $a_{v, \max }-v$ plot in the following. The numerical results indicate increasing running speed may result in amplification on both vertical and lateral acceleration response. As shown in Fig. 9, the inclusion of the lateral uniform ground motion may lead to considerable amplification on the $a_{l, \max }-v$ plot of lateral vehicle's response but little influence on the vertical response of the $a_{v, \max }-v$ plot drawn in Fig. 10. One of the reasons is that the induced guidance factor $\kappa_{y, k}$ caused by lateral movements of magnetic wheels does not lead noticeable variation to vertical levitation forces. 


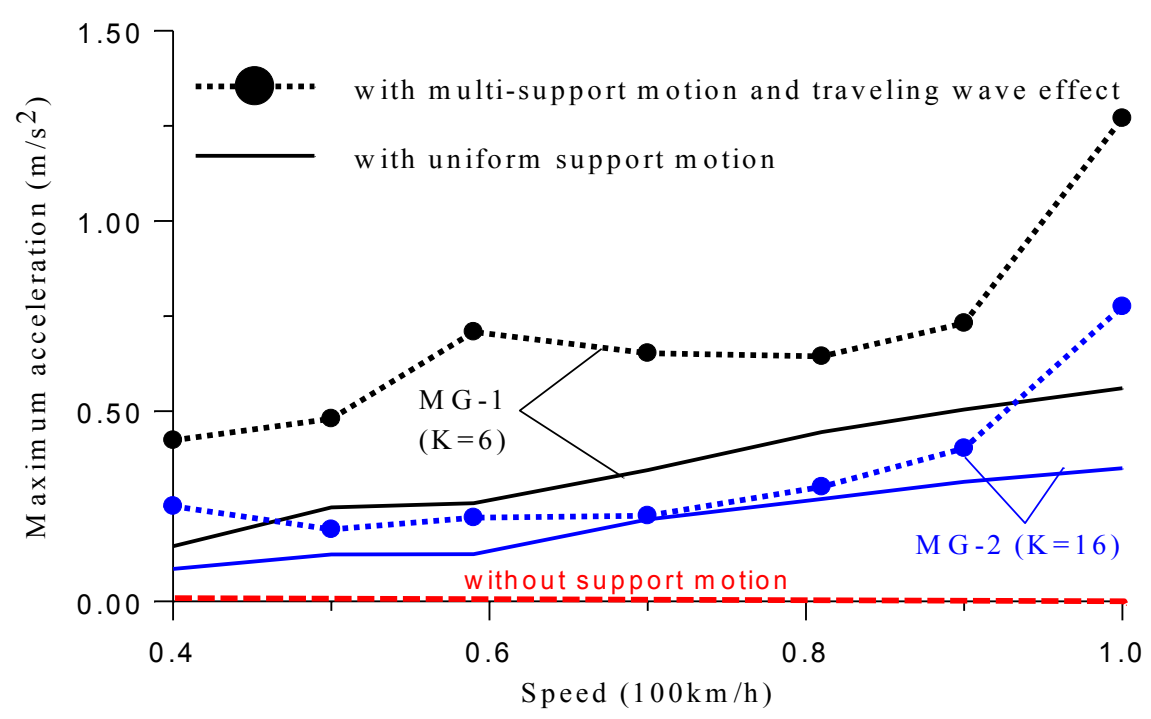

Figure $9 a_{1, \max }-v$ plot of the maglev vehicle.

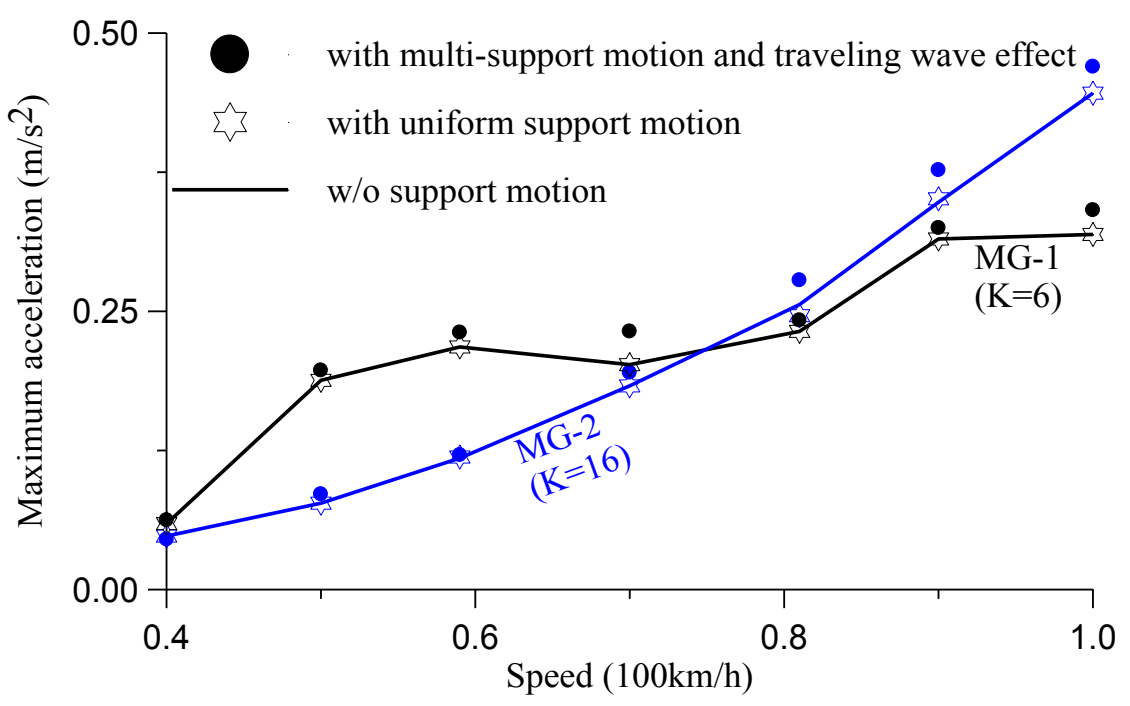

Figure $10 a_{v, \max }-v$ plot of the maglev vehicle.

\subsection{Effect of multi-support motion}

For demonstration, the support foundations of the guideway are assumed to anchor at soft-soil site with propagation wave velocity of $v_{s}(=100 \mathrm{~m} / \mathrm{s})$ and intensity of the seismic wave does not decay when traveling in the soft-soil along the gudieway. Thus the lateral ground motion acting at the right support of a guideway girder has always a time lag of $L / v_{s}(=20 / 100=0.2 \mathrm{~s})$ behind the left one (see Fig. 2). Including the traveling seismic wave effect in the following examples, the numerical results of simulation are plotted in Fig. 9 as well. As expected, the multi-support motion to the maglev vehicle/guideway system plays an important role in amplifying lateral response of the maglev vehicles. Moreover, the amplified response of the MG-1 is significantly high- 
er than that of the MG-2. The reason is that the MG-2 (with 16 magnets) has more magnets equipped with $\mathrm{PI}+\mathrm{LQR}$ controllers to provide larger tuning gains to guide the lateral response of the vehicle.

\subsection{Effect of number of magnets on reducing lateral vibration}

In Examples 7.2 and 7.3, the numerical results indicate that increasing the number of supported magnets can effectively suppress lateral seismic-induced vibration of the moving maglev vehicles on guideways. To demonstrate this, let the maglev vehicle be equipped with different number of supported magnets, respectively, and move on the guideways at constant speed $100 \mathrm{~km} / \mathrm{h}$. The corresponding $a_{l, \max ^{-}} v$ plot for lateral response of the moving vehicle has been depicted in Fig. 11 . The results show increasing the number of PI + LQR hybrid controllers can offer more tuning gains to control lateral vibration of the moving maglev vehicles.

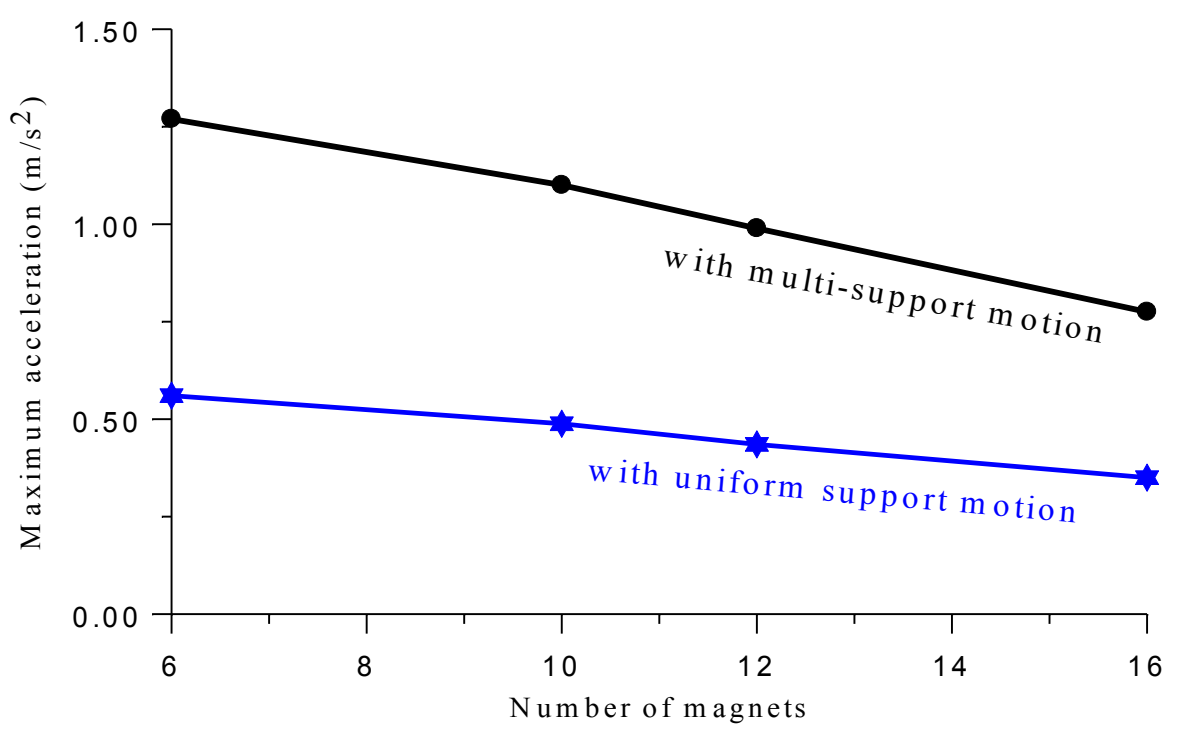

Figure 11 Comparison of control performance of support magnets

\section{CONCLUDING REMARKS}

Based on the incremental-iterative method, this study establishes a theoretical framework to perform nonlinear seismic analysis and vibration control for a maglev vehicle moving on guideways. By combining PI tuning method with LQR algorithm, the proposed PI + LQR hybrid controller is an efficient tool to control lateral seismic-induced vibration of moving maglev vehicles. From the numerical investigations, the following conclusions are addressed: (1) In carrying out the nonlinear seismic response analysis of maglev-vehicle/guideway system, lateral multi-support motion induced by traveling seismic wave plays a key role in affecting response of moving maglev vehicles; (2) Increasing the number of supported magnets to regulate magnetic forces can reduce and guide lateral seismic-induced vibration of moving maglev vehicles; (3) Even the PGA of lateral seismic inputs is scaled down to 11 gal, the lateral multi-support motion still affects the lateral response of moving maglev vehicle significantly. It means that lateral seismic vibration of moving 
maglev vehicle may dominate dynamic interaction behaviors of maglev transport.

Acknowledgements This research was partially supported by the National Science Council in Taiwan through the Grants: NSC 99-2221-E-032-020-MY3. The author would like to express his gratitude for this financial support by the National Natural Science Foundation of China (Grant No. 10972196) when he visited Zhejiang University for academic research of 2012.

\section{References}

[1] Y.B. Yang J.D. Yau and Y.S. Wu, Vehicle-Bridge Interaction Dynamics. Singapore, World Scientific, 2004.

[2] Y.B. Yang and H.H Hung, Wave propagation for train-induced vibrations - a finite/infinite element approach. Singapore, World Scientific, 2009.

[3] G. Samavedam, S. Kokkins, F. Raposa, M. Thompson, and G. Anagnostopoulos, Assessment of CHSST Maglev for U.S. Urban Transportation, U.S. Department of Transportation, Federal Transit Administration, Report Number FTA-MD-26-7029-2002.1. 2002.

[4] J. Shi, Q. Wei, and Y. Zhao, Analysis of dynamic response of the high-speed EMS maglev vehicle/guideway coupling system with random irregularity, Veh. Sys. Dyn., 45:1077-1095, 2007.

[5] J. Shi and Y.J. Wang. Dynamic response analysis of single-span guideway caused by high speed maglev train, Latin American Journal of Solids and Structures, 8:213-228, 2011.

[6] D.H. Shi, Maglev rail technology in Japan and its potential applications, Journal of Transportation Systems Engineering and Information Technology, 7(5):1-4, 2007.

[7] S.D. Kwon, J.S., Lee, J. W. Moon, and M. Y. Kim, Dynamic interaction analysis of urban transit maglev vehicle and guideway suspension bridge subjected to gusty wind, Eng. Struct., 30:3445-3456, 2008.

[8] A. Bittar and R.M. Sales, $\mathrm{H}_{2}$ and $\mathrm{H}_{\infty}$ control for maglev vehicles, IEEE Control Sys. Mag. 18(4):18-25, 1998.

[9] G. Bohn and G. Steinmetz, The electromagnetic levitation and guidance technology of the Transrapid test facility Emsland, IEEE Trans. Mag., 20(5):1666-1671, 1984.

[10] Y. Cai, S.S. Chen, D.M. Rote, and H.T. Coffey, Vehicle/guideway dynamic interaction in maglev systems, J. Dyn. Sys. Meas. Cont., 118:526-530, 1996.

[11] Y. Cai and S.S. Chen, Dynamic characteristics of magnetically-levitated vehicle systems, A Mech. Rev., 50(11):647-670, 1997.

[12] X.J. Zheng, J.J. Wu, and Y.H. Zhou, Numerical analyses on dynamic control of five-degree-of-freedom maglev vehicle moving on flexible guideways, J. Sound Vib., 235:43-61, 1997.

[13] X.J. Zheng, J.J. Wu, and Y.H. Zhou, Effect of spring non-linearity on dynamic stability of a controlled maglev vehicle and its guideway system, J. Sound Vib., 279:201-215, 2005.

[14] C.F. Zhao and W.M. Zhai, Maglev vehicle/guideway vertical random response and ride quality, Veh. Sys. Dyn., 38(3):185-210, 2002.

[15] J.D. Yau, Vibration control of maglev vehicles traveling over a flexible guideway, J. Sound Vib., 321:184200, 2009.

[16] J.D. Yau, Response of a maglev vehicle moving on a series of guideways with differential settlement, J. Sound Vib., 324:816-831, 2009.

[17] J.D. Yau, Interaction response of maglev masses moving on a suspended beam shaken by horizontal ground motion, J. Sound Vib., 329:171-188, 2010.

[18] J.D. Yau, Response of a maglev vehicle moving on a two-span flexible guideway, J. Mech., 26(1):95-103, 2010.

[19] J.D. Yau, Aerodynamic vibrations of a maglev vehicle running on flexible guideways under oncoming wind actions, J. Sound Vib., 329:1743-1759, 2010.

[20] Y.B. Yang and J.D. Yau, An iterative interacting method for dynamic analysis of the maglev trainguideway/foundation-soil system, Eng. Struct., 33:1013-1024, 2011. 
[21] J.D. Yau. Lateral vibration control of a low-speed maglev vehicle in cross winds, Wind and Structures, 15(3):263-283, 2012.

[22] P. Leger, I. M. Ide, and P. Paultre, Multiple-support seismic analysis of large structures, Computers \& Structures, 36(6):1153-1158, 1990.

[23] H. Xia, Y. Han, N. Zhang, W. Guo, Dynamic analysis of train-bridge system subjected to non-uniform seismic excitations, Earthq. Eng. \& Struct. Dyna., 35(12):1563-1579, 2006.

[24] D. Aldo and R. Alfred, Design of an integrated electromagnetic levitation and guidance system for Swiss Metro, EPE'99, Lausanne, Swiss, 1999.

[25] T.T. Soong, Active structural control: theory and practice, Longman Scientific \& Technical, Essex, England, 1990.

[26] K.J. Astrom and T. Hagglund, Automatic Tuning of PID Controllers, Instrument Society of America, USA, 1988.

[27] K. Ogata, Modern Control Engineering, $3^{\text {rd }}$ ed, Prentice-Hall, Englewood Cliffs, N.J., 1997.

[28] J.D. Yau, Vehicle/bridge interactions of a rail suspension bridge considering support movements, Interaction and Multistage Mechanics: an International Journal, 2(3):263-276, 2009.

[29] J.D. Yau and Y. B. Yang, Vertical accelerations of simple beams due to successive loads traveling at resonant speeds, J. Sound Vib., 289:210-228, 2006.

[30] Y.J. Wang, Q.C. Wei, J. Shi, and X.Y. Long. Resonance characteristics of two-span continuous beam under moving high speed trains. Latin American Journal of Solids and Structures, 7(2):185-199, 2010.

[31] J.D. Yau, Lateral vibration control of a low-speed maglev vehicle in cross winds. Wind and Structures, 15(3):263-283, 2012. 